Ahd El-Maksood A. M.

\title{
DESIGN AND ANALYSIS THE OPERATION OF SCHMITT TRIGGER CIRCUIT IN RADIATION ENVIRONMENT
}

The object of research is the effect of gamma radiation on the characteristics of the operation amplifier, and consequently the behavior of the output voltage waveforms of Schmitt trigger circuit. One of the most problematic is the effect of the circuit elements, reference voltage, input frequency, input DC-voltage and bias voltage effects, on the operation of the proposed Schmitt trigger circuit. In the course of the research, the used Op Amp can be exposed to different types of radiation. As a result of the research it is shown that the threshold levels of Schmitt trigger circuit increased when operates in nuclear radiation environment.

From the experimental work, computer simulation, and results analysis, the conclusions could be deduced, that Operation of operational amplifiers in gamma radiation environment show serious changes on their electrical characteristics. As a result, the Schmitt trigger circuit exposed to gamma radiation range from $3 k G y$ up to $20 k G y$, at $10 \mathrm{~Hz}$, where, its output voltage waveforms are shown to be independent on the gamma-dose. On the other hand, at frequency of $4.0 \mathrm{kHz}$, a severe effect are noticed, where the lower threshold level $\left(V^{L T L}\right)$ increase from $-5.35 \mathrm{~V}$ up to $-3.58 \mathrm{~V}$, while the upper threshold voltage level $\left(\mathrm{V}^{U T L}\right)$ is slightly increased from $4.21 \mathrm{~V}$ to $5 \mathrm{~V}$, as a function of the same gamma doses. The obtained experimental results are shown to be in close agreement with those obtained from programming the Schmitt trigger equations to computer.

In the future, the proposed approaches show that, whenever the Op Amp circuits are used in gamma radiation environment, it preferable to be operate at low frequency levels, where the output voltage waveform of Schmitt trigger circuit are shown to be independent on gamma dose but at high frequency the effect increased as a function of same gamma dose.

Keywords: Schmitt trigger, Op-Amps, threshold levels, radiation environment, electronic circuit, gamma radiation.

\section{Introduction}

Schmitt trigger is a special type of bistable device that has two threshold voltages (i. e. stable states). These are often used to control the input and operation of logic gates and IC's. The Schmitt trigger input causes the device to change logic states abruptly when a given voltage level known as the threshold voltage is reached. This feature is exploited in many applications as an astable multivibrator or for increasing the noise immunity in circuit inputs. Essentially, it prevents erratic switching between states when the input voltages hover around the critical input level. This allows for reliable triggering to occur when the input is changing very slowly [1].

The Schmitt trigger is a comparator that uses hysteresis. It basically has two thresholds lower threshold level ( $V^{L T L}$ ) and upper threshold voltage level $\left(V^{U T L}\right)$, one on each side of the reference voltage. This gives a buffer zone for the rejection of noise and interference of the input signal. The hysteresis enables the comparator to turn on at one voltage value and possibly turn off at another voltage value. Hysteresis in the Schmitt trigger also ensures that the output is the same frequency as the input for noisy input signals that may cross the threshold several times while rising and falling. The Schmitt trigger is especially useful for slowly varying and noisy input signals [1, 2].
Thus, the object of research is the effect of gamma radiation on the characteristics of the operation amplifier, and consequently the behavior of the output voltage waveforms of Schmitt trigger circuit. Also, the aim of this article is to shed further light on the rules to be considered whenever the proposed system is applied in some outer space applications.

\section{Methods of research}

It is often useful to compare a voltage to a known reference level; this can be done electronically using the comparator circuit shown in Fig. 1.

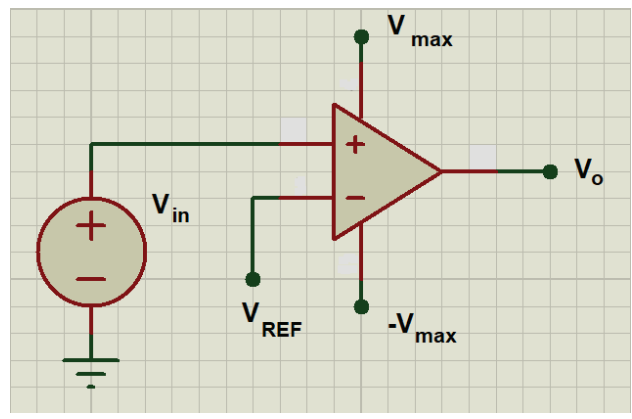

Fig. 1. Comparator Circuit 
For input signals exceeding the reference voltage $V_{R E F}$, the output saturates at $V_{\max }$, while for input signals less than $V_{R E F}$, the output saturates a $-V_{\max }$, as indicated in the voltage transfer characteristic shown in Fig. 2 [3].

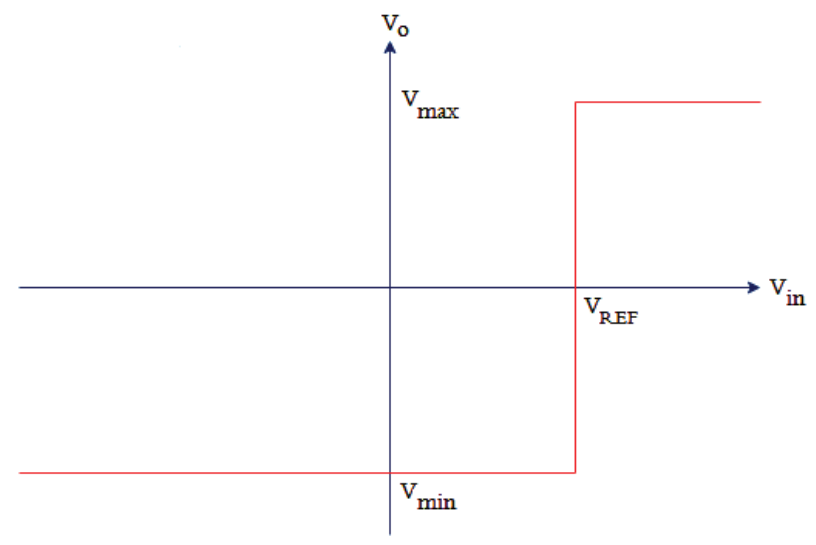

Fig. 2. Voltage transfer characteristic [4]

This circuit comes in several configurations; let's discuss only the basic inverting Schmitt trigger or regenerative comparator (Fig. 3).

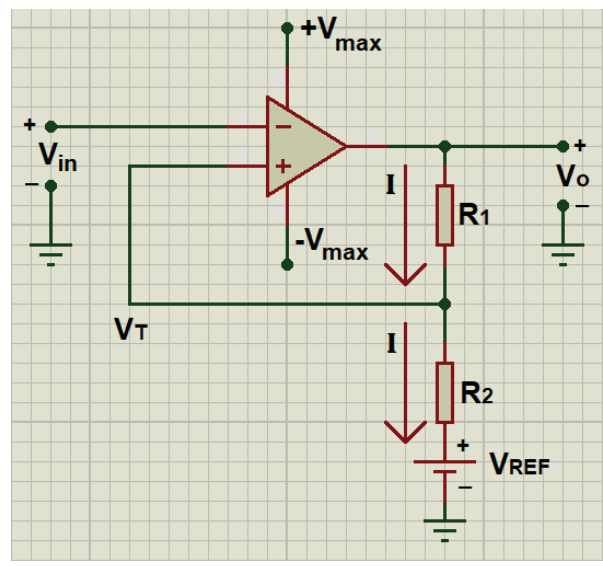

Fig. 3. Schmitt trigger circuit

The regenerative comparator or Schmitt trigger, shown in Fig. 3, is a special circuit which acts like a switch that changes state at two different thresholds. These are called the upper and lower threshold or the positive and negative going their threshold. The difference in the two threshold levels is called the hysteresis voltage [5]. The word of hysteresis is used to describe a situation in which the system has memory. That is, the output at any particular time depends not only on the present value of the input but also on past values. For example, for an input voltage of $V_{\text {in }}=0$ there are two possible values of $V_{o}$, depending on the direction in which $V_{i n}=0$ [6].

In the context of a voltage comparator, hysteresis means that the output will switch when the input increases to one level but will not switch back until the input falls below a different level. In some applications, hysteresis is a desirable characteristic because it prevents the comparator from switching back and forth in response to random noise fluctuations in the input [7,8].

One class of comparator known as the Schmitt trigger uses positive feedback to speed up the switching cycle.
With positive feedback, a small change in the input is amplified and fed back, in phase, to reinforce itself, thereby leading rapidly to larger changes [9]. The feedback effectively increases the gain becomes larger than the open loop gain making the comparator swinging faster to one of the saturation levels unless a sufficiently large input is applied to overcome the feedback [10].

In this circuit, the input is connected to the inverting terminal and a voltage divider is connected across the noninverting terminal between $V_{o}$ and a fixed reference voltage $V_{\text {ref }}$. Fig. 4 shows the resulting transfer characteristic (called a hysteresis loop). This characteristic shows that the output switches to $+V_{\max }$ when $V_{\text {in }}$ falls below a lower trigger level ( $L T L)$, but will not switch to $-V_{\max }$ unless $V_{i n}$ rises past as upper trigger level $(U T L)$. The arrows indicate the portions of the characteristic followed when the input is increasing (upper line) and when it is decreasing (lower line) [10].

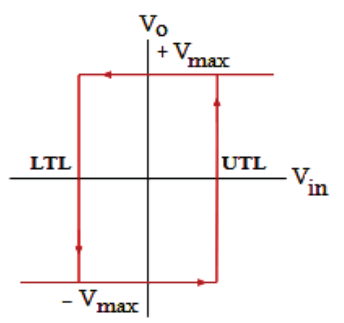

Fig. 4. Transfer characteristic of Schmitt trigger circuit [4]

This observation about hysteresis indicates an important application of the Schmitt trigger that is this circuit can be used as a binary memory device. Where, since the output depends on past values of the input, it is possible to apply a voltage to the input and then remove that voltage. The trigger circuit remembers whether the voltage was above or below the reference level. It is possible to therefore «write» one of two possible values into this memory [11].

The most important use made of the Schmitt trigger is to convert a very slowly varying input voltage into an output having an abrupt (almost discontinuous) waveform. Occurring at a precise value of input voltage the regenerative comparator used as a squaring circuit is illustrated in Fig. 5. The input signal is arbitrary except that it has a large enough excursion to carry the input beyond the limits of the hysteresis range. The output is a square wave as shown, the amplitude of which is independent of the peak-to-peak value of the input waveform. The output has much faster leading and trailing edges than dose the input [12].

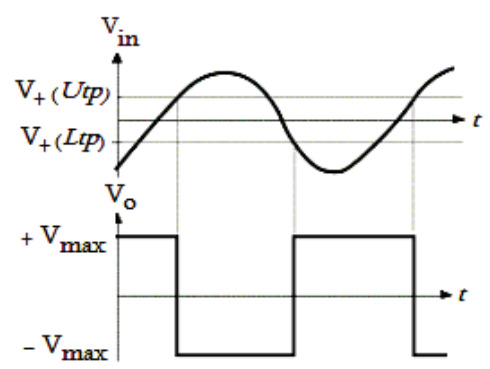

Fig. 5. Response of the inverting Schmitt trigger to an arbitrary input signal [4] 
Schmitt trigger action is a double threshold comparator process. The current flowing through $R_{1}$ and $R_{2}$ for the circuit in Fig. 3 is:

$$
I=\frac{V_{r e f}-V_{+}}{R_{2}}=\frac{V_{+}-V_{o}}{R_{1}} \Rightarrow V_{+}=\frac{V_{r e f} R_{1}+V_{o} R_{2}}{R_{1}+R_{2}} .
$$

The output $V_{o}$ can have two values, $\pm V_{\max }$. Consequently, $V_{+}$will assume just two trip points' values:

$$
\begin{aligned}
& V_{+}^{(U t p)}=\frac{R_{2}}{R_{1}+R_{2}} V_{\text {ref }}+\frac{R_{1}}{R_{1}+R_{2}} V_{\text {max }}, \\
& V_{+}^{(L t p)}=\frac{R_{2}}{R_{1}+R_{2}} V_{\text {ref }}-\frac{R_{1}}{R_{1}+R_{2}} V_{\text {max }},
\end{aligned}
$$

when $V_{i n}<V_{+}^{(U t p)}, V_{o}$ is high, and when $V_{i n}<V_{i n}<V_{+}^{(L t p)}, V_{o}$ is low [13].

As can be seen in Fig. 5, $V^{-}$must fall to this value of $V^{+}$before the comparator switches to $+V_{\max }$ therefore:

$$
L T L=\frac{R_{2}}{R_{1}+R_{2}} V_{r e f}+\frac{R_{1}}{R_{1}+R_{2}}\left(-V_{\max }\right) .
$$

Similarly, when $V_{o}=+V_{\max }, V_{\text {in }}$ must rise to:

$$
U T L=\frac{R_{2}}{R_{1}+R_{2}} V_{r e f}+\frac{R_{1}}{R_{1}+R_{2}}\left(+V_{\max }\right) .
$$

In these equations, $+V_{\max }$ is the maximum positive output (a positive number) and $-V_{\max }$ is the maximum negative output voltage (a negative number).

Quantitatively, the hysteresis of a Schmitt trigger is defined to be the difference between the input trigger levels. From (4), (5):

Hysteresis $=U T L-L T L$.

$$
\text { Hysteresis }=\frac{R_{1}}{R_{1}+R_{2}}\left(+V_{\max }\right)-\frac{R_{1}}{R_{1}+R_{2}}\left(-V_{\max }\right) .
$$

If the magnitudes of the maximum output voltages are equal, let's obtain:

$$
\text { Hysteresis }=\frac{2 R_{1} V_{\max }}{R_{1}+R_{2}} \text {. }
$$

The comparator is called an inverting Schmitt trigger because the output is high when the input is low, and vice versa. Fig. 3 shows a noninverting Schmitt trigger, where for this circuit, the lower and the upper trigger levels are:

$$
\begin{aligned}
& L T L=\frac{-R_{1}}{R_{2}}\left(+V_{\max }\right) . \\
& U T L=\frac{R_{1}}{R_{2}}\left|-V_{\max }\right| .
\end{aligned}
$$

Notice that these equations permit the magnitudes of $+V_{\max }$ and $-V_{\max }$ to be different values [14].

Fig. 4 shows noninverting Schmitt trigger transfer characteristic where a reference voltage of $0 \mathrm{~V}$ is implied since $V_{-}=0$. Let's start with $V_{\text {in }}$ as a large positive voltage. This causes the output voltage, $V_{o}$, to be at $+V_{\max }$, the op-amp saturation voltage. The noninverting voltage, $V_{+}$, is calculated by writing a node equation at the $V_{+}$node as follows:

$$
\frac{V_{+}-V_{i}}{R_{1}}+\frac{V_{+}-V_{o}}{R_{2}}=0 \text {. }
$$

So,

$$
V_{+}\left(\frac{1}{R_{1}}+\frac{1}{R_{2}}\right)=\frac{V_{i}}{R_{1}}+\frac{V_{o}}{R_{2}} .
$$

Let's start reducing the magnitude of $V_{\text {in }}$ to find the switching point. Since $V_{-}=0$ and $V_{+}=V_{-}$(once the opamp comes out of saturation), set (11) to zero to obtain:

$$
V_{i}=\frac{-R_{1} V_{o}}{R_{2}}=\frac{-R_{1}}{R_{2}} V_{\max }
$$

As $V_{\text {in }}$ is reduced from a large positive, the output voltage, $V_{o}$, is switched from $+V_{\max }$ to $-V_{\max }$ at the point where $V_{+}$goes to zero. This happens at the point where $V_{i n}$ reaches $-R_{1} V_{\max } / R_{2}$. As the input voltage, $V_{i n}$ is reduced further, $V_{o}$ remains at $-V_{\max }$.

If to increase the input voltage from a large negative value, the output voltage will switch to $+V_{\max }$ when $V_{+}=0=V_{\text {. }}$. Hence the switching takes place at:

$$
V_{i}=\frac{-R_{1} V_{o}}{R_{2}}=\frac{-R_{1}\left(-V_{\max }\right)}{R_{2}}=\frac{+R_{1}}{R_{2}} V_{\max } .
$$

$V_{o}$ remains at $+V_{\max }$ as $V_{i}$ is further increased past $+R_{1} V_{\max } / R_{2}[10]$.

Schmitt triggers use hysteresis to guard against noise that would otherwise cause rapid switching back and forth between the two output states, when the inputs are close to the threshold. Finally, the symbol for Schmitt triggers in electronic circuits is a triangle with a hysteresis symbol as shown in Fig. $6[15,16]$ :

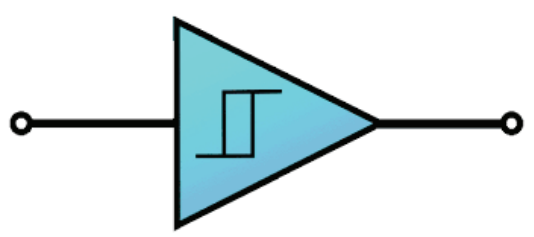

Fig. 6. Symbol for Schmitt triggers in electronic circuits [4]

The proposed Schmitt trigger circuit (Fig. 3) was designed based on LM741 CN op-amp, with conjunction of $R_{1}=4.6188 \mathrm{k} \Omega$ and $R_{2}=9.99 \mathrm{k} \Omega$, where these values were measured precisely using an accurate A programmable automatic RCL meter, Model PM 6306, manufactured by Fluke. The op-amp was biased with $\pm 15 \mathrm{~V}$.

\section{Research results and discussion}

3.1. Effect of Circuit Elements on Schmitt Trigger. In the investigated circuit, the resistors $R_{1}$ and $R_{2}$ form a voltage divider, which determines the threshold points of the trigger. Fig. 7 and 8 show the output waveforms of the Schmitt trigger plotted at different values of $R_{1}$ and $R_{2}$. The operating conditions were kept at input signal $\left(V_{p p}\right)$ equals $20.8 \mathrm{~V}$; reference voltage $\left(V_{r e f}\right)$ equals $2 \mathrm{~V}$ and frequency of $10 \mathrm{~Hz}$. 
The output square waves were shown to be switched nearly between $\pm 15 \mathrm{~V}$, for each value of $R_{1}$ and $R_{2}$.

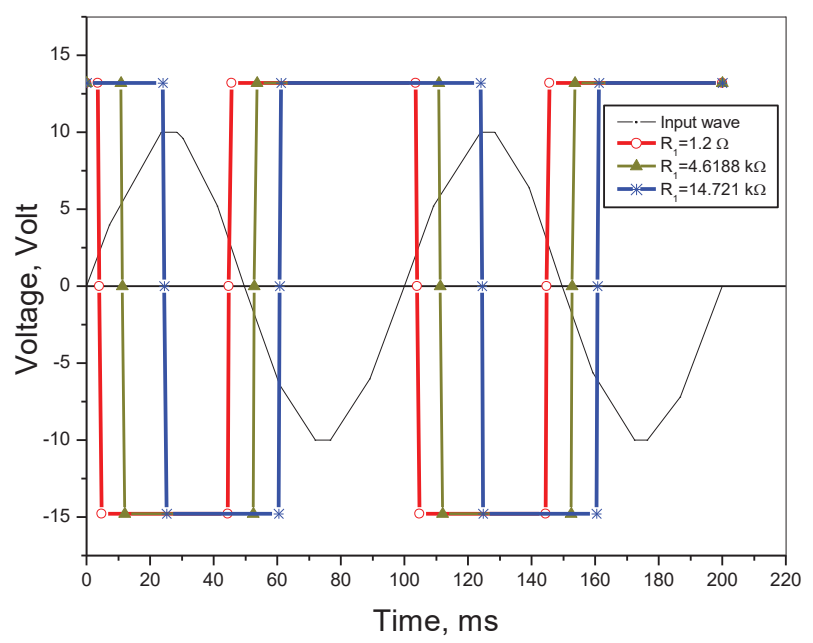

Fig. 7. Effect of $R_{1}$ on output voltage of Schmitt trigger for LM741 CN, $V_{\text {ref }}=2 \mathrm{~V}, V_{p p}=20.8 \mathrm{~V}$ and $f=10 \mathrm{~Hz}$

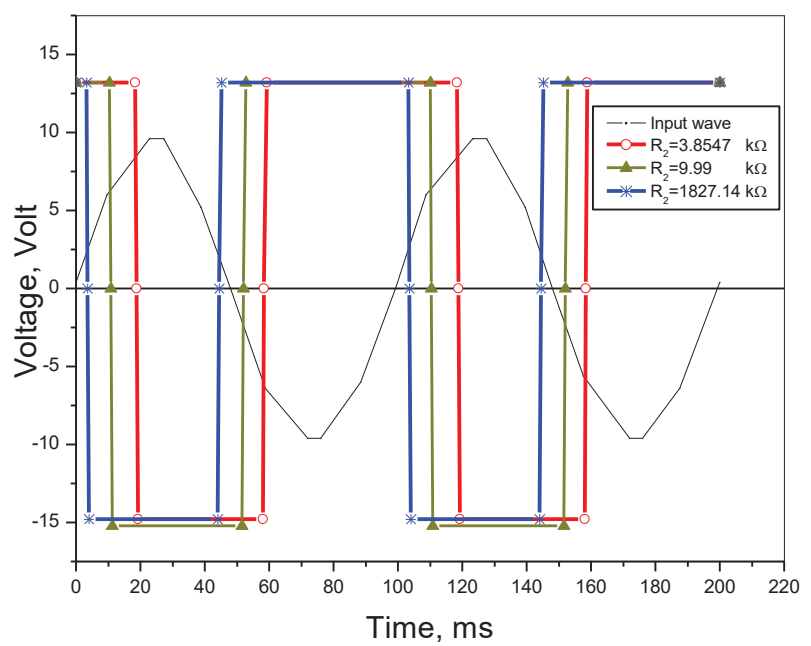

Fig. 8. Effect of $R_{2}$ on output voltage of Schmitt trigger for LM741 CN, $V_{r e f}=2 \mathrm{~V}, V_{p p}=20.8 \mathrm{~V}$ and $f=10 \mathrm{~Hz}$

It is clearly shown that, the experimental lower- and upper- thresholds of the Schmitt trigger could be deduced for each value of $R_{1}$ and $R_{2}$ (Fig. 7 and 8). Also, programming (8), (9), to computer, applying $\mathrm{C}++$ language, and one gets the theoretical lower- and upper- thresholds. From which, the experimental and theoretical upper threshold level (UTL) and lower threshold level (LTL) can be plotted as a function of $R_{1}, R_{2}$ (Fig. 9 and 10). The theoretical thresholds are in close agreement with experimental values.

The $U T L$ and $L T L$ values were shown to be function of $R_{1}$ and $R_{2}$, where the experimental UTL increases sharply from 2.6 up to $10 \mathrm{~V}$, while $L T L$ decreases sharply, from 2.4 down to $-6.6 \mathrm{~V}$ with increasing $R_{1}$ (Fig. 9). On the other hand, it is noticed that increasing $R_{2}$ from $3.2591 \mathrm{k} \Omega$ up to $149.4 \mathrm{k} \Omega$ resulting a pronounced decrease in experimental UTL from 9.8 down to $2.8 \mathrm{~V}$, while $L T L$ increases rapidly from -6.2 up to $2.2 \mathrm{~V}$. Finally, for higher values of $R_{2}$, both UTL and LTL are shown to be nearly constant (Fig. 10).

Fig. 11 and 12 show the relations between the positive- and negative- pulse width values as a function of operating input signal voltage $\left(V_{p p}\right)$, plotted at different values of $R_{1}$ and $R_{2}$.

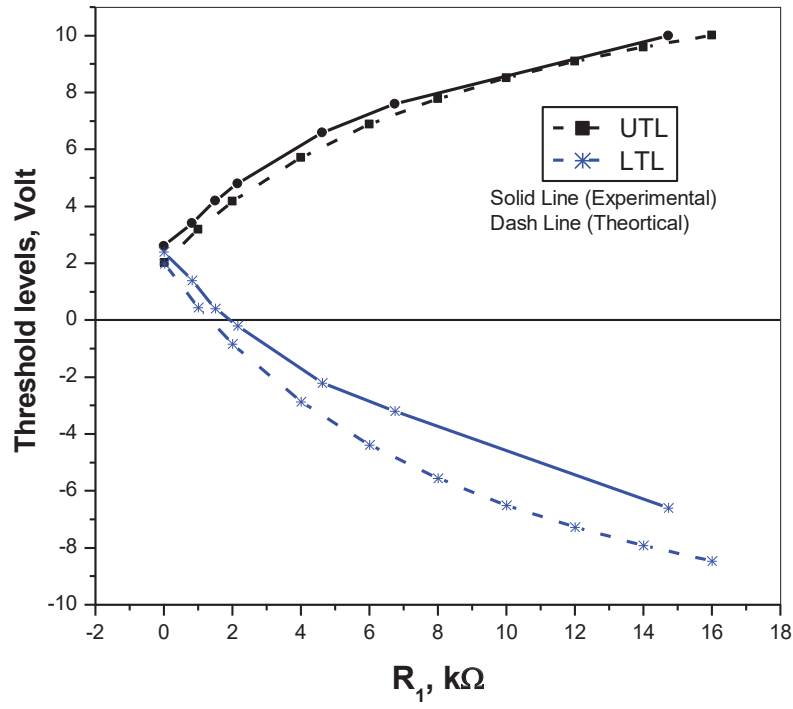

Fig. 9. Effect of $R_{1}$ on the experimental and theoretical, UTL and LTL of Schmitt trigger

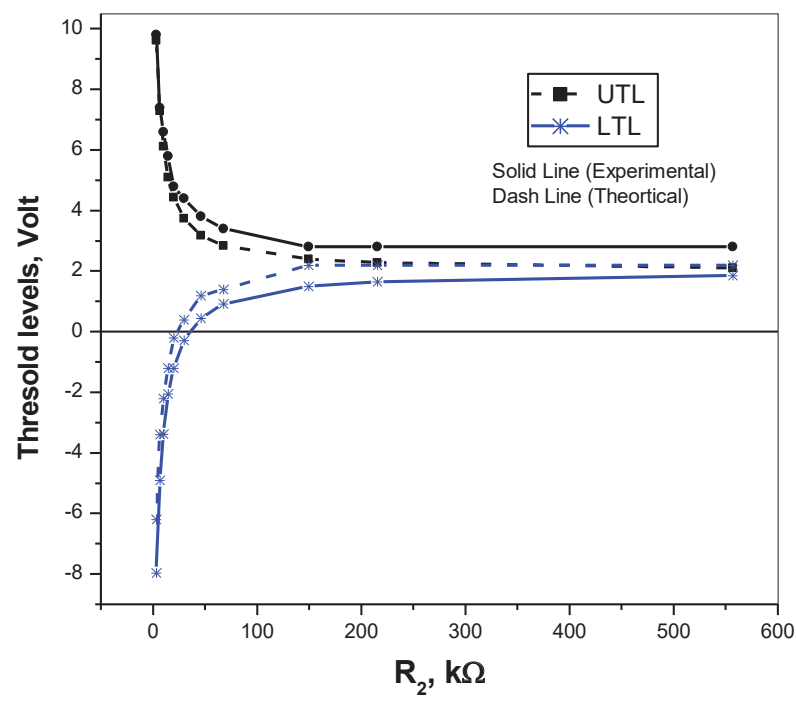

Fig. 10. Effect of $R_{2}$ on the experimental and theoretical, UTL and LTL of Schmitt trigger

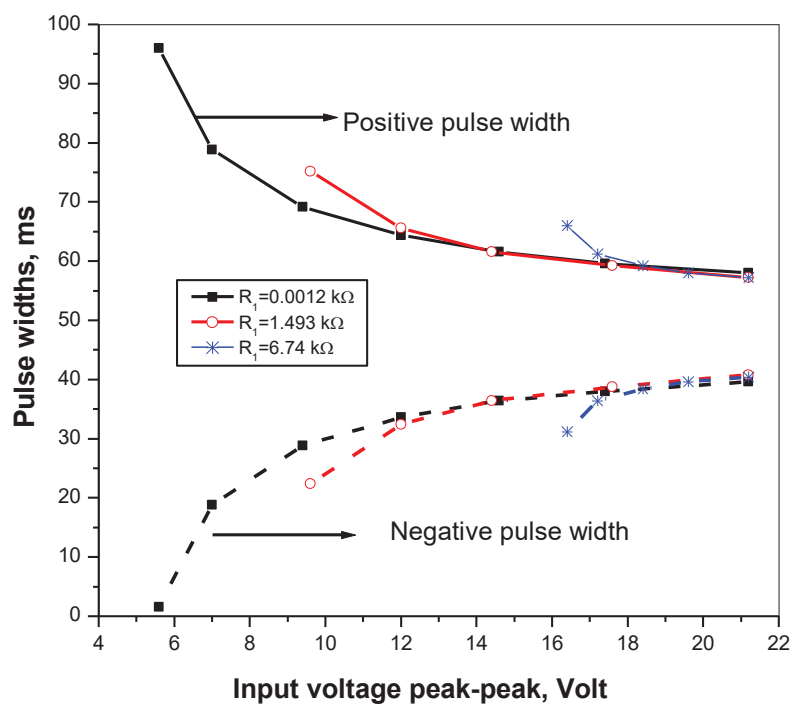

Fig. 11. Positive pulse width (solid lines) and negative pulse width (dashed lines) of Schmitt trigger for LM741 CN versus input voltage peak-peak $\left(V_{p p}\right)$ at different values of $R_{1}$ 


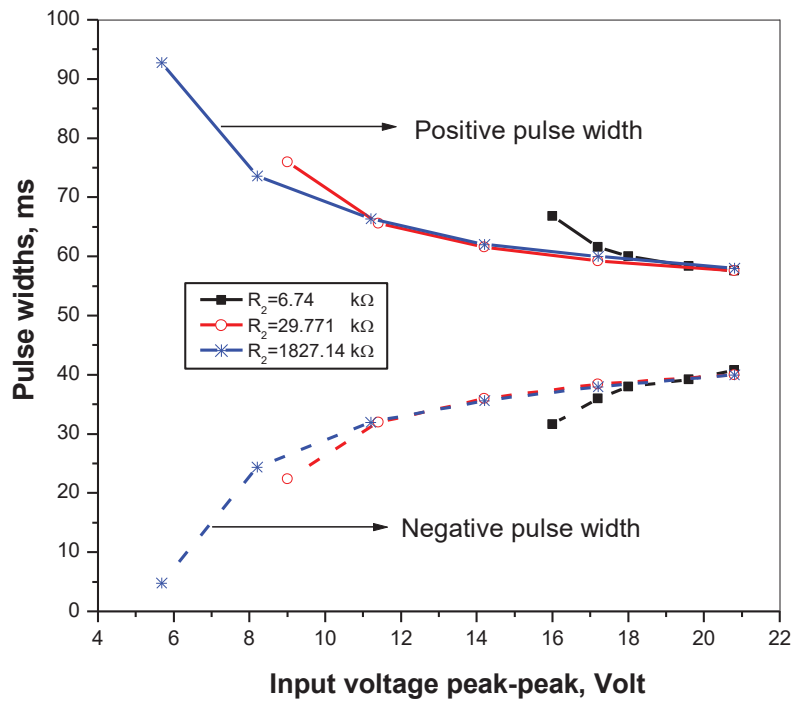

Fig. 12. Positive pulse width (solid lines) and negative pulse width (dashed lines) of Schmitt trigger for LM741 CN versus input voltage peak-peak $\left(V_{p p}\right)$ at different values of $R_{2}$

Considering the positive pulse width, its value is shown to decrease, while the negative pulse width is shown to increase with increasing $V_{p p}$ for different values of $R_{1}$ and $R_{2}$. Also, the values of $R_{1}$ and $R_{2}$ determine the range of operating input signal voltage, where for low values of $R_{1}(1.2 \Omega)$, the range of $V_{p p}$ is larger than in the case of high value of $R_{1}(6.74 \mathrm{k} \Omega)$. Also, this range decreased with increasing the value of $R_{1}$ (Fig. 11). On the contrary the behavior with $R_{2}$ (Fig. 12).

3.2. Effect of Circuit Resistances on Input Signal Amplitude. For many applications, it is necessary to use a wide range of input signal amplitude, so the study was extended to investigate the effects of $R_{1}$ and $R_{2}$ on the input signal amplitude (Fig. 13 and 14). It is clear from the two figures that the input signal amplitude is directly proportional with $R_{1}$, and $1 / R_{2}$, i. e., for extending the upper limit of the input signal amplitude; it must choose large $R_{1}$ and small $R_{2}$.

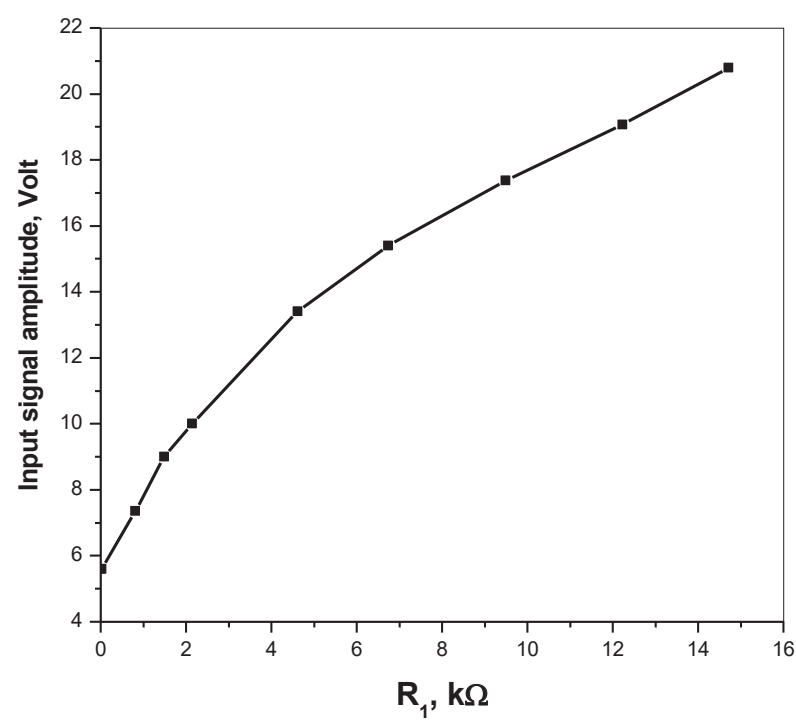

Fig. 13. Effect of $R_{1}$ on the input switch voltage value (input $V_{p p}$ ) of Schmitt trigger for LM741 CN at bias $\pm 15 \mathrm{~V}, V_{\text {ref }}=2 \mathrm{~V}$ and $f=10 \mathrm{~Hz}$

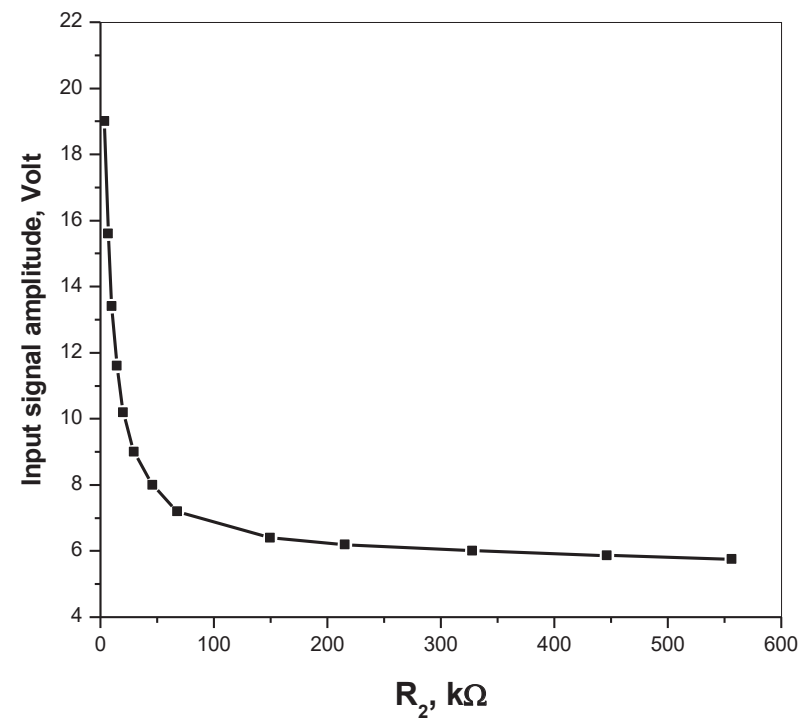

Fig. 14. Effect of $R_{2}$ on the input switch voltage value (input $V_{p p}$ ) of Schmitt trigger for LM741 CN at bias $\pm 15 \mathrm{~V}, V_{r e f}=2 \mathrm{~V}$ and $f=10 \mathrm{~Hz}$

In an attempt to draw a complete picture about the effect of the passive elements on the operation of the proposed Schmitt trigger circuit, the output signal pulse width was plotted as a function of $R_{1}$ and $R_{2}$, for different input signal amplitude values (Fig. 15 and 16).

In Fig. 15, the range of $R_{1}$ change at which the output signal appear depends on the value of $V_{p p}$, where at low value of $V_{p p}(9 \mathrm{~V})$ the operating range of $R_{1}$ from $1.2 \Omega$ up to $2.2931 \mathrm{k} \Omega$, while for high value of $V_{p p}(20.8 \mathrm{~V})$ its operating range is from $1.2 \Omega$ up to $14.721 \mathrm{k} \Omega$. Also, in Fig. 15 for each value of $V_{p p}$ input signal, positive pulse width increases, while negative pulse width decreases. Finally, as shown in Fig. 16 at low value of $R_{2}$ equals $14.721 \mathrm{k} \Omega$ for $V_{p p}$ input signal equals $10.2 \mathrm{~V}$ and $R_{2}$ equals $3.8547 \mathrm{k} \Omega$ for $V_{p p}$ input signal equals $20.8 \mathrm{~V}$, the positive pulse width is high, while the negative pulse width is low, above this value of $R_{2}$ for each values of $V_{p p}$ input, the positive pulse width decreases, while the negative pulse width increases and then both pulse widths remain constant.

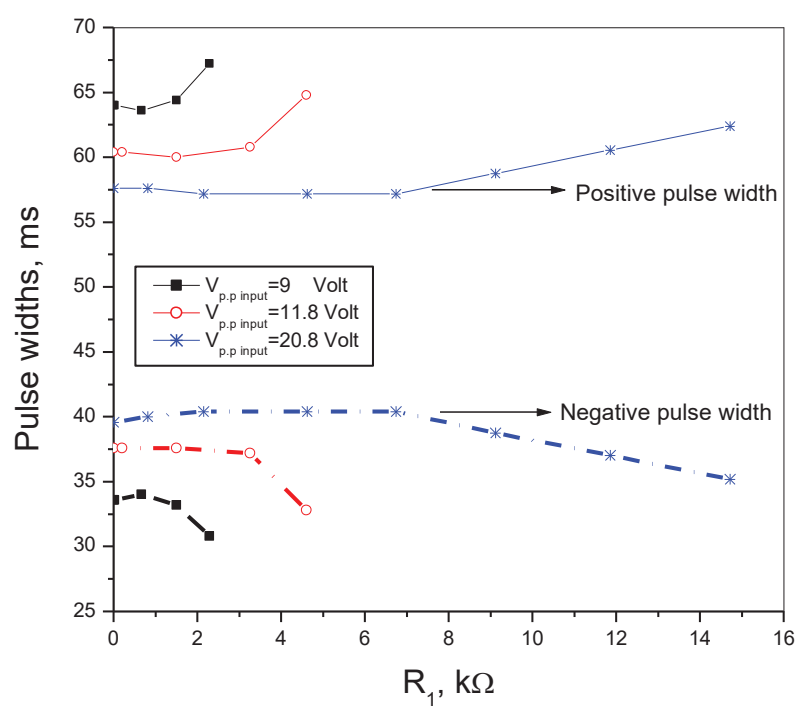

Fig. 15. Positive pulse widths (solid lines) and negative pulse widths (dash lines) of Schmitt trigger for LM741 CN versus $R_{1}$ at different values of $V_{p p \text { input }}$ (bias $\pm 15 \mathrm{~V}, V_{r e f}=2 \mathrm{~V}$, and $f=10 \mathrm{~Hz}$ ) 


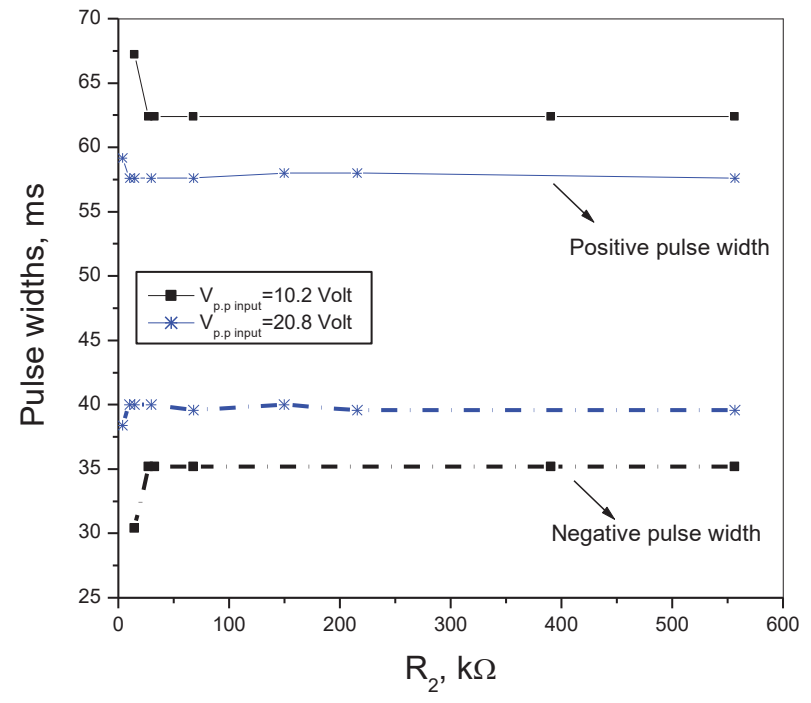

Fig. 16. Positive pulse width (solid lines) and negative pulse width (dash lines) of 5chmitt trigger for LM741 $\mathrm{CN}$ versus $B_{2}$ at different values of $V_{p p \text { input }}$ (bias $\pm 15 \mathrm{~V}, \mathrm{~V}_{\text {ref }}=2 \mathrm{~V}$, and $f=10 \mathrm{~Hz}$ )

\subsection{Effects of Operating Conditions.}

3.3.1. Reference Voltage. Fig. 17 shows the output voltages of the Schmitt trigger circuit plotted at different reference voltage values of $0,2,4$ and $6 \mathrm{~V}$, respectively. All measurements were carried out at input signal $\left(V_{p p}\right)$ of $20.8 \mathrm{~V}$ and frequency of $10 \mathrm{~Hz}$. As the input voltage rises from low value (almost $0 \mathrm{~V}$ ) towards $U T L$, the output will remain constant at $V_{\max }$. When the input exceeds UTL the output will drop down to $-V_{\max }$. At this point, reducing the input voltage will not cause the output to jump to $V_{\max }$ immediately. This only happens when the input voltage is reduced to $L T L$ [17]. The theoretical values of $U T L$ and $L T L$ are given applying (4) and (5).

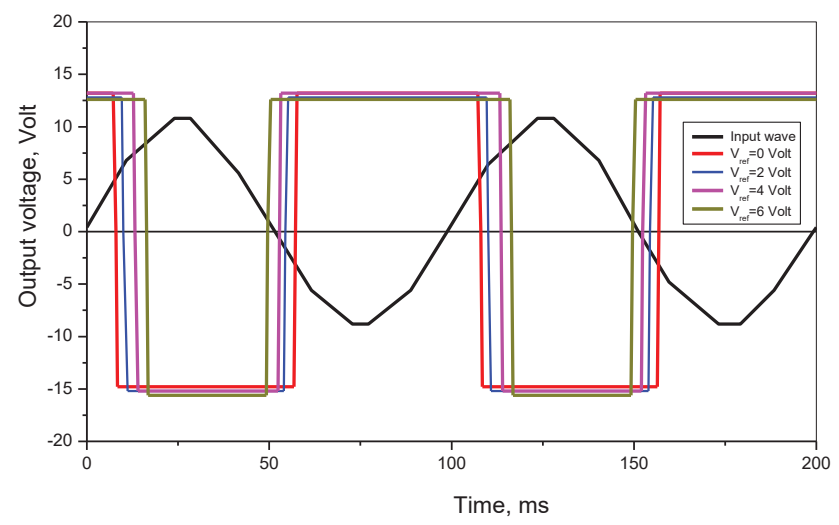

Fig. 17. Effect of $V_{\text {ref. }}$ on the output waveform of Schmitt trigger for LM741 CN at bias $\pm 15 \mathrm{~V}, V_{p p \text { input }}=20.8 \mathrm{~V}$ and $f=10 \mathrm{~Hz}$

Fig. 18 shows the dependence of both the positive and negative pulse width of the output signal on $V_{r e f}$. It is clearly shown that for constant input signal $(20.8 \mathrm{~V}$; $V_{p . p}$, at frequency $10 \mathrm{~Hz}$ ), the width of both positiveand negative- pulse widths of the output signal are directly dependent on $V_{\text {ref }}$. For $V_{\text {ref }}$ ranging from 0 up to $7 \mathrm{~V}$, the positive pulse width increases from $52 \mathrm{~ms}$ up to $75.6 \mathrm{~ms}$, and the negative pulse width decreases from $45.6 \mathrm{~ms}$ down to $22 \mathrm{~ms}$.

The effect of reference voltage on the input signal amplitude range was also studied, Fig. 19. It is clearly shown that, input signal amplitude range is direct function of the reference voltage.

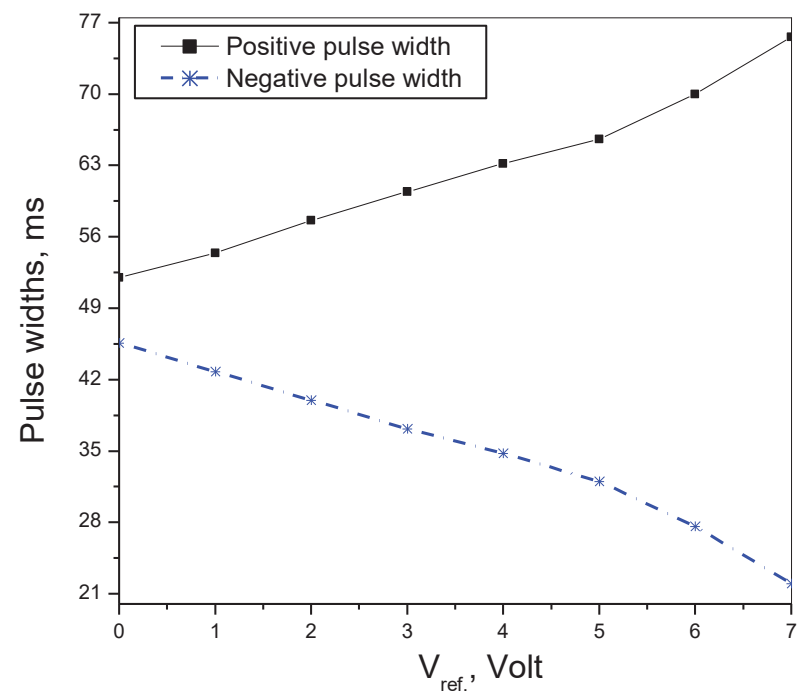

Fig. 18. Effect of $V_{\text {ref }}$ on the pulse widths of output of Schmitt trigger for LM741 CNat bias $\pm 15 \mathrm{~V}, V_{p p \text { input }}=20.8 \mathrm{~V}$ and $f=10 \mathrm{~Hz}$

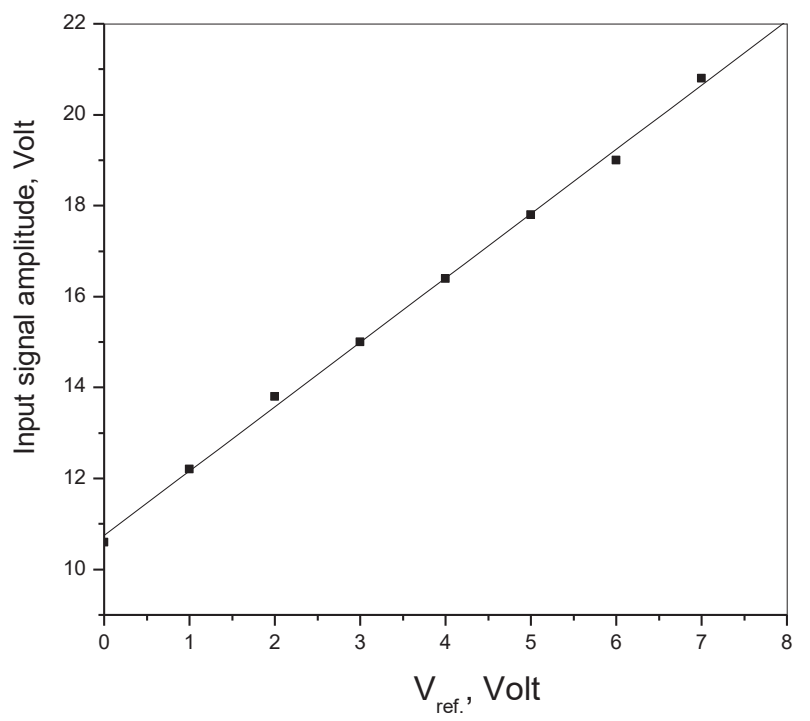

Fig. 19. Effect of $V_{r e f}$ on the input switch voltage value (input $V_{p p}$ ) of Schmitt trigger for LM741 CN at bias $\pm 15 \mathrm{~V}$ and $f=10 \mathrm{~Hz}$

3.3.2. Effect of Input Frequency. The study was extended to investigate the effect of the input signal frequency on the operation of the proposed Schmitt trigger circuit. Fig. 20 shows the output curves at a constant input signal value of $20.8 \mathrm{~V}\left(V_{p p}\right)$ and different reference voltage $(0,2$, and $4 \mathrm{~V})$ and at frequency value of $3 \mathrm{kHz}$. The output voltage is shown to be a square wave with slightly slew rate. Table 1 illustrates the experimental values of both $U T L$ and $L T L$, measured at the mentioned reference voltage values and at two different frequencies.

Fig. 21 shows the dependence of threshold levels on the $V_{\text {ref }}$ at different input frequency values of $10 \mathrm{~Hz}, 3 \mathrm{kHz}$, and $6 \mathrm{kHz}$. It is clearly shown that, as $V_{\text {ref }}$ increases (from 0 to $7.0 \mathrm{~V}$ ), the value of both $U T L$ and $L T L$ increase linearly. Also, the values of $U T L$ and $L T L$ are dependent on the input frequency, whereas the frequency increases, UTL increases, while the $L T L$ decreases, when measured at certain $V_{\text {ref }}$ value. At low reference voltage $(0 \mathrm{~V})$ the value of $U T L$ 
changes from $5.11 \mathrm{~V}$ up to $8.81 \mathrm{~V}$, while at high reference voltage $(7.0 \mathrm{~V})$ it changes slightly from $10.33 \mathrm{~V}$ up to $10.92 \mathrm{~V}$, when the input frequency changes from $10 \mathrm{~Hz}$ to $6 \mathrm{kHz}$. On the other hand, the value of $L T L$ changes from $-3.24 \mathrm{~V}$ down to $-6.78 \mathrm{~V}$, while at high reference voltage $(7.0 \mathrm{~V})$ it changes from $1.39 \mathrm{~V}$ down to $-4.24 \mathrm{~V}$, when the frequency changes from $10 \mathrm{~Hz}$ to $6.0 \mathrm{kHz}$.

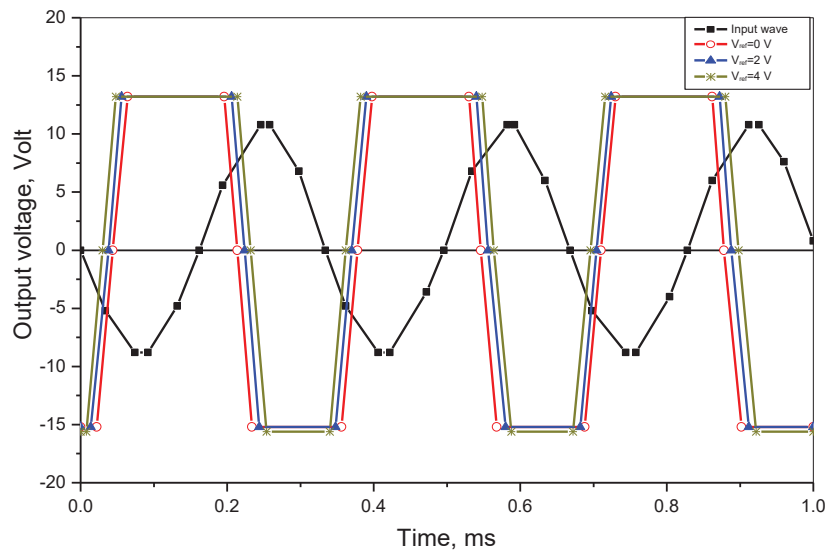

Fig. 20. Effect of $V_{\text {ref. }}$ on the output waveform of Schmitt trigger for LM741 CN at bias $\pm 15 \mathrm{~V}, V_{p p \text { input }}=20.8 \mathrm{~V}$ and $f=3 \mathrm{kHz}$

Table 1

The experimental values of both UTL and LTL with varying reference voltage and frequency

\begin{tabular}{|c|c|c|c|}
\hline$F, \mathrm{~Hz}$ & $V_{\text {ref, }} \mathrm{V}$ & UTL, $\mathrm{V}$ & LTL, $\mathrm{V}$ \\
\hline \multirow{3}{*}{10} & 0 & 5.200 & -3.210 \\
& 2 & 6.614 & -2.6920 \\
& 4 & 7.241 & -0.0758 \\
& 6 & 8.264 & 0.0220 \\
\hline \multirow{3}{*}{3000} & 0 & 6.820 & -5.330 \\
& 2 & 7.346 & -4.627 \\
& 4 & 8.078 & -3.895 \\
\hline
\end{tabular}

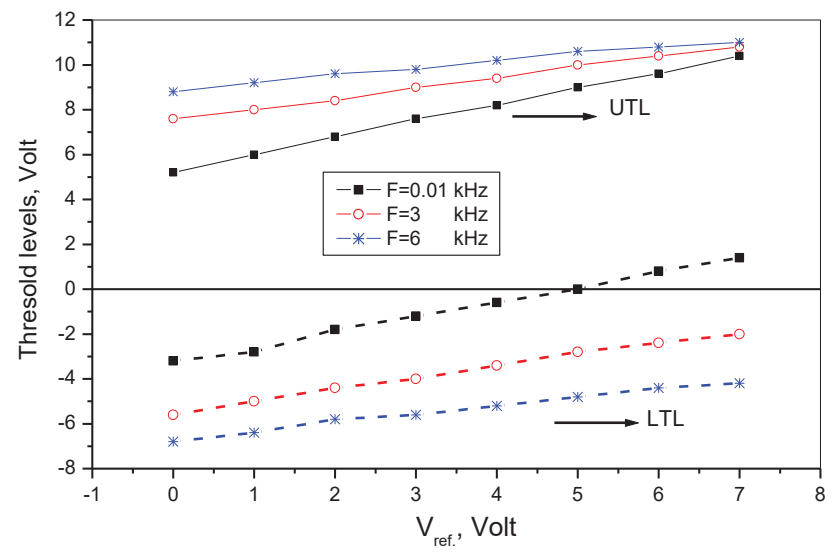

Fig. 21. UTL (solid lines) and LTL (dash lines) of Schmitt trigger forLM741 CN versus $V_{\text {ref }}$ at different frequency values at $V_{p p \text { input }}=20.8 \mathrm{~V}$

The dependence of the positive- and negative- pulse width values on $V_{p . p}$ was plotted at different $V_{\text {ref }}(0,3$ and $6 \mathrm{~V}$ ) and frequencies at $10 \mathrm{~Hz}$ and $3 \mathrm{kHz}$, as shown in Fig. 22 and 23. It is clearly shown that for all $V_{\text {ref }}$ and frequencies, the positive- pulse width decreases as
$V_{p p}$ increases, and the negative pulse width is shown to increase as $V_{p p}$ increases. For both cases the rate of change on pulse width is a function of $V_{r e f}$ rather than frequency.

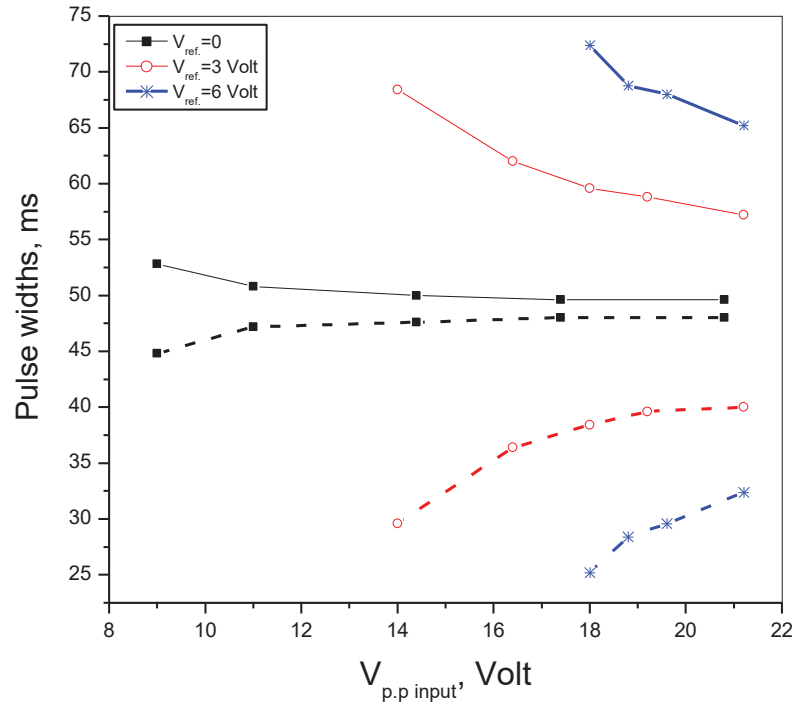

Fig. 22. Positive pulse width (solid lines) and negative pulse width (dash lines) of Schmitt trigger for LM741 CN versus $V_{p p \text { input }}$ with different values of $V_{\text {ref }}$ at $f=10 \mathrm{~Hz}$

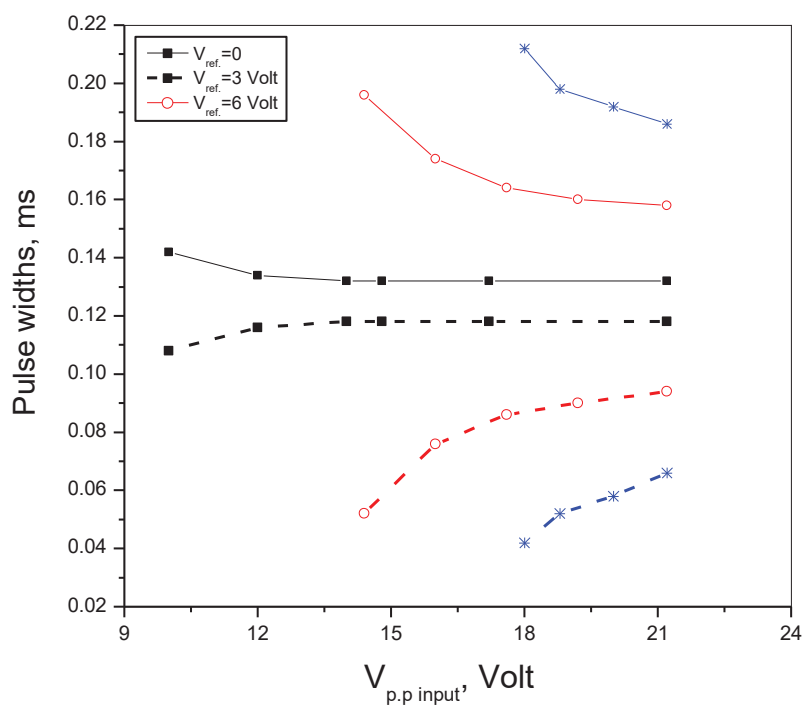

Fig. 23. Positive pulse width (solid lines) and negative pulse width (dash lines) of Schmitt trigger for LM741 CN versus $V_{p p \text { inpu }}$ at different values of $V_{\text {ref }}$ at $f=3 \mathrm{kHz}$

3.3.3. Effect of Input DC Offset voltage. The effect of the DC-offset voltage of the input signal on the output of the Schmitt trigger circuit was investigated. The input signal was $20.8 V_{p p}$ with frequency $10 \mathrm{~Hz}$. Fig. 24 shows the input and output traces of the LM $741 \mathrm{CN}$ Schmitt trigger plotted at different values of input DC offset voltage $(-2.4,-0.4,0,1.6,2.8$ and $3.8 \mathrm{~V})$.

As the input offset voltage increases $(-2.4$ to $3.8 \mathrm{~V})$, the positive pulse width decreases from $67.045 \mathrm{~ms}$ down to $44.31819 \mathrm{~ms}$, while the negative pulse width increases from $31.818 \mathrm{~ms}$ up to $54.545 \mathrm{~ms}$ (Fig. 25).

On the other hand, the increase of input offset voltage causes the LTL to increase, while the UTL remain constant, as shown in Fig. 26. 

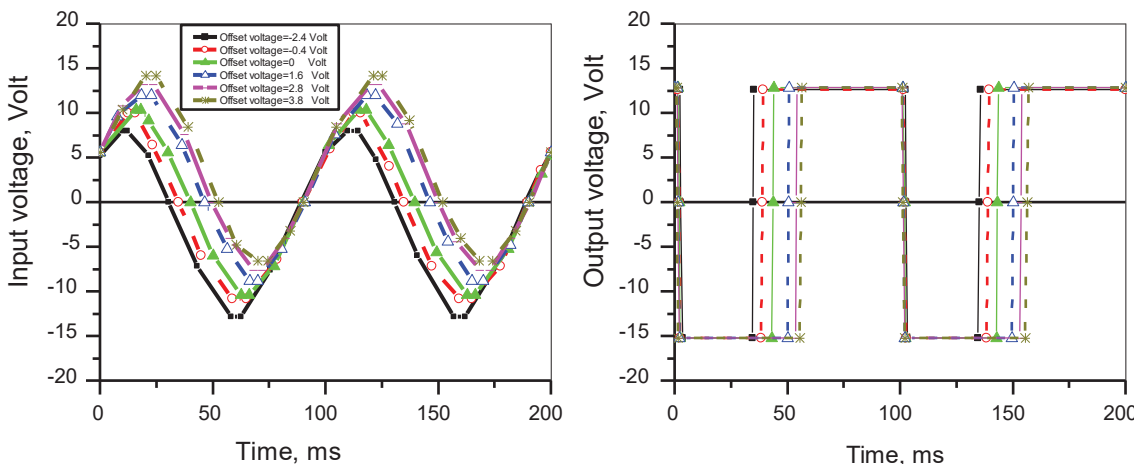

Fig. 24. Effect of offset voltage of input signal on output waveform of Schmitt trigger at bias $\pm 15 \mathrm{~V}, f=10 \mathrm{~Hz}, V_{r e f}=2 \mathrm{~V}$ and $V_{p p \text { input }}=20.8 \mathrm{~V}$

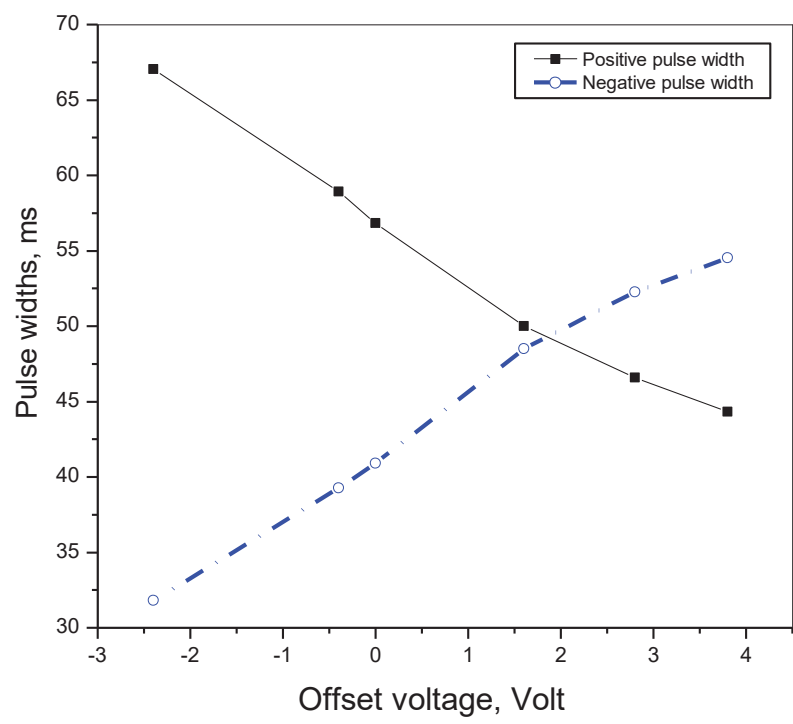

Fig. 25. Effect of offset voltage on output pulse widths of Schmitt trigger at bias $\pm 15 \mathrm{~V}, f=10 \mathrm{~Hz}, V_{r e f}=2 \mathrm{~V}$ and $V_{p p \text { input }}=20.8 \mathrm{~V}$

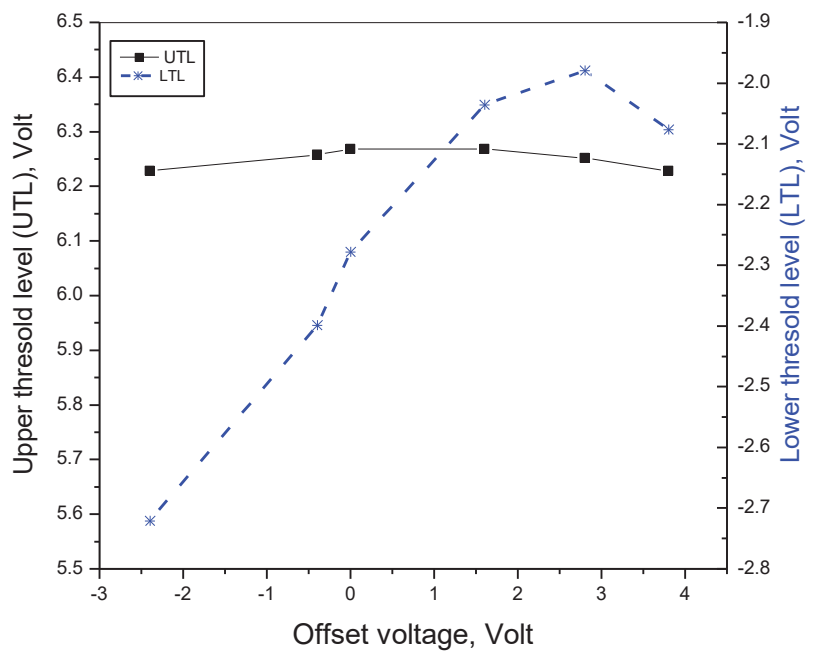

Fig. 26. Effect of offset voltage on threshold levels of Schmitt trigger at bias $\pm 15 \mathrm{~V}, f=10 \mathrm{~Hz}, V_{\text {ref }}=2 \mathrm{~V}$ and $V_{\text {p input }}=20.8 \mathrm{~V}$

3.4. Bias Effect. The effect of the input bias of the operational amplifier on the output waveform of the Schmitt trigger circuit is shown in Fig. 27, where the input signal is the sine wave and the output signal is the square wave of the Schmitt trigger measured at frequency $10 \mathrm{~Hz}, V_{\text {ref }}=2 \mathrm{~V}, V_{p p}$ input $=$ $=20 \mathrm{~V}$ and biases of op-amp are $\left(-V_{\max }=0,+V_{\max }=5 \mathrm{~V}\right)$, $\left(-V_{\max }=0,+V_{\max }=15 \mathrm{~V}\right)$ and $\left(-V_{\max }=-15,+V_{\max }=15 \mathrm{~V}\right)$. The maximum and minimum amplitudes of the output waveform are direct functions of the bias voltage of the op-amp, where the maximum amplitude is nearly equal to $+V_{\max }$, while the minimum amplitude is nearly equal $-V_{\max }$ of the op-amp.

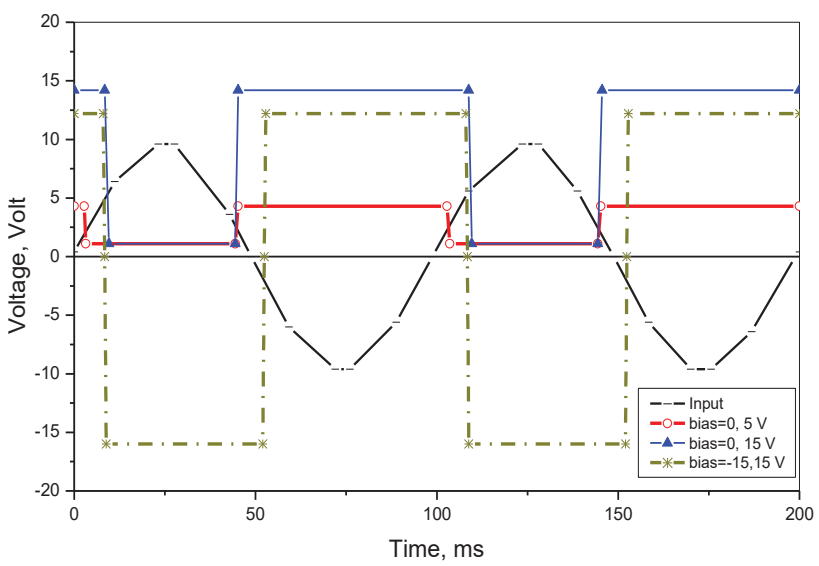

Fig. 27. Effect of bias voltage of op-amp on output waveform of Schmitt trigger

3.5. Effect of Gamma-Ray Exposure on the Schmitt Trigger Circuit. The effect of gamma-ray exposure on the output waveform of the Schmitt triggers circuit. Figs. 28 and 29 show the obtained results for samples irradiated up to $20 \mathrm{kGy}$, and plotted at two frequency values of $10 \mathrm{~Hz}$ and $4 \mathrm{kHz}$, respectively.

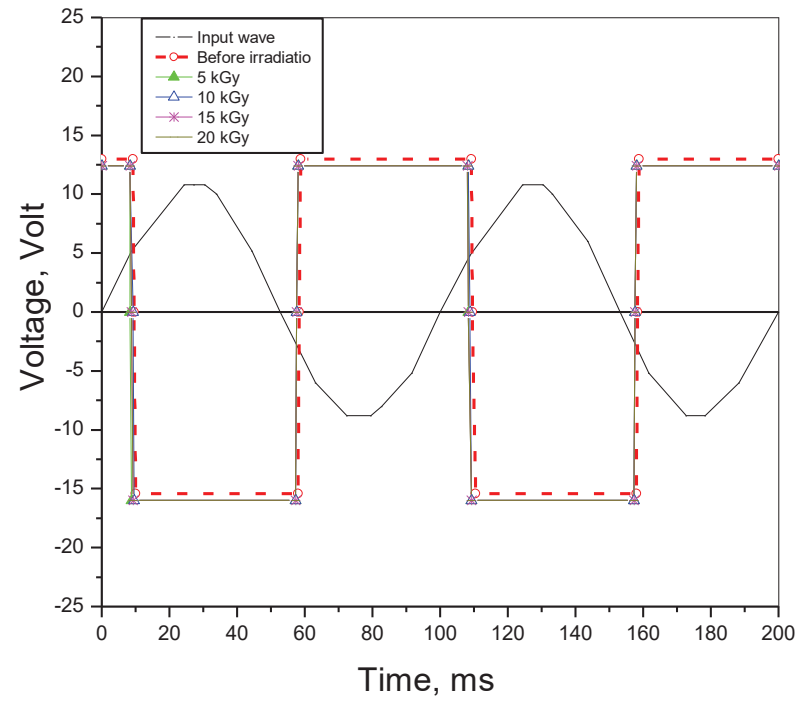

Fig. 28. Gamma-radiation effect on the Schmitt trigger circuit output waveform at bias $\pm 15 \mathrm{~V}, V_{\text {ref }}=0 \mathrm{~V}, f=10 \mathrm{~Hz}$ 


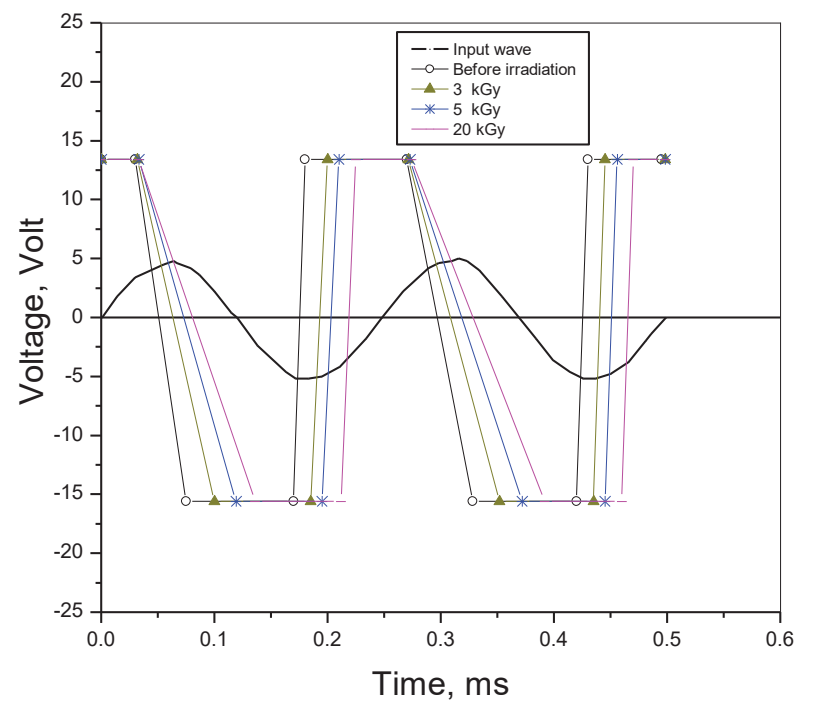

Fig. 29. Gamma-radiation effects on the Schmitt trigger circuit output waveform at bias $\pm 15 \mathrm{~V}, V_{\text {ref }}=0 \mathrm{~V}, f=4 \mathrm{kHz}$

It is clearly shown that, at low frequency $(10 \mathrm{~Hz})$, the output waveform of the Schmitt trigger is independent on the gamma-dose. On the other hand, for higher frequency levels $(4.0 \mathrm{kHz})$, a severe effect was noticed, where the lower threshold voltage level ( $V^{L T L}$ ) of the Schmitt trigger circuit is shown to increase. The matter, which can be mainly attributed to the increases in the offset voltage of the op-amp due to gamma ray exposure [18, 19].

Fig. 30 shows the relation between threshold values and gamma exposure levels at higher frequency $(4 \mathrm{kHz})$.

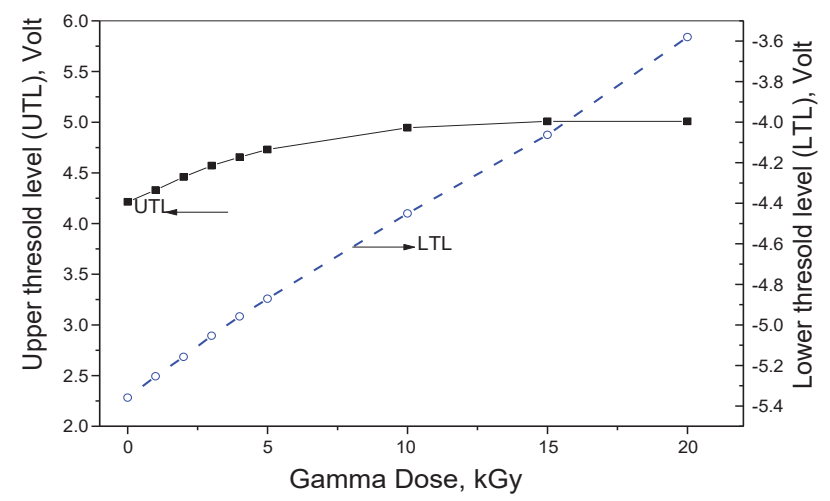

Fig. 30. Increase in the upper (UTL) - and in the lower (LTL) - triggering levels Values due to gamma-exposure at $f=4 \mathrm{kHz}$

A severe effect were noticed, where the lower threshold level $\left(V^{L T L}\right)$ of Schmitt trigger circuit increasing (from $-5.35 \mathrm{~V}$ to $-3.58 \mathrm{~V}$ ) while the upper threshold level ( $\left.V^{U T L}\right)$ is slightly increases (from $4.21 \mathrm{~V}$ to $5 \mathrm{~V}$ ), as a function of the same gamma doses.

\section{Conclusions}

1. Operation of operational amplifiers in gamma radiation environment show serious changes on their electrical characteristics. As a result, the Schmitt trigger circuit exposed to gamma radiation range from $3 \mathrm{kGy}$ up to $20 \mathrm{kGy}$, at
$10 \mathrm{~Hz}$, where its output voltage waveforms are shown to be independent on the gamma-dose. On the other hand, at frequency of $4.0 \mathrm{kHz}$, a severe effect are noticed, where the lower threshold level ( $\left.V^{L T L}\right)$ increase from $-5.35 \mathrm{~V}$ up to $-3.58 \mathrm{~V}$, while the upper threshold voltage level ( $V^{U T L}$ ) is slightly increased from $4.21 \mathrm{~V}$ to $5 \mathrm{~V}$, as a function of the same gamma doses.

2. The obtained experimental results are shown to be in close agreement with those obtained from programming the Schmitt trigger equations to computer.

\section{References}

1. ECE 3274 LAB Project 3, «Digital Applications of the Op$A m p »(2004)$. Available at: https://www.courses.ece.vt.edu/ ece3274/Project3.pdf

2. Als, A. (1999). Schmitt Trigger.

3. Schmitt Trigger using Op-Amp. Available at: https://www. circuitstoday.com/schmitt-trigger-using-op-amp

4. Electronics-Lab: Electronic Projects, Embedded News and Online Community. Available at: https://www.electronics-lab.com/

5. Abrar, M. M. (2017). Design and Implementation of Schmitt Trigger using Operational Amplifier. International Journal of Engineering Research and Applications, 7 (1), 5-9. doi: http:// doi.org/10.9790/9622-0701040509

6. Leach, D. P., Malvino, A. P., Goutam, S. (2011). Digital Principles and Applications. New Delhi: Tata McGraw Hill, Special Indian Edition, 250-252.

7. Godse, A. P., Godse, U. A. (2016). Analog \& Digital Electronics. Pune: Technical Publications, 3, 15-30.

8. Vardhan, K. V., Santhoshini, K. M., Musala, S., Pabbisetty, V. N. L. (2019). Schmitt Trigger Circuits using Various Active Devices. International Journal of Engineering and Advanced Technology, 9 (1S5), 143-146. doi: http://doi.org/10.35940/ijeat.a1035. 1291s52019

9. Schmitt, O. H. (1938). A thermionic trigger. Journal of Scientific Instruments, 15 (1), 24-26. doi: http://doi.org/10.1088/0950$7671 / 15 / 1 / 305$

10. Kundra, S., Soni, P. (2012). Low Power Schmitt Trigger. Innovative Systems Design and Engineering, 3 (2), 43-51.

11. Carpenter, S. R. (1991). Electronic Design. Redwood city: Benjamin Cummings publishing company, Inc, 1024.

12. Sophomore Physics Laboratory (2002). Analog Electronic. Ch. 5. Virginio de Oliveira Sannibale.

13. Millman, J. (1979). Microelectronic: Digital and Analog Circuits and systems. Mc Graw-Hill, Inc. 881.

14. Theodre, F., Bogart, J. R. (1991). Electronic Devices and Circuits. Singapore: Prentice Hall.

15. Using Schmitt Trigger for Low Slew-Rate Input (2002). Available at: www.actel.com/documents/SchmittTrigger AN.pdf

16. Bernard, M. F., Dusseau, L., Buchner, S., McMorrow, D., Ecoffet, R., Boch, J. et. al. (2007). Impact of Total Ionizing Dose on the Analog Single Event Transient Sensitivity of a Linear Bipolar Integrated Circuit. IEEE Transactions on Nuclear Science, 54 (6), 2534-2540. doi: http://doi.org/10.1109/tns.2007.910229

17. Xiaoming, J. et. al. (2013). Transient Ionizing Radiation effect of Bipolar Operational Amplifiers to Pulsed X-rays. Proceedings of IPAC. Shanghai, 3687-3689.

18. Ashry, H. A., Soliman, F. A. S., Swidan, A. M., El-Ghanam, S. M., Abdel Rahman, W. A. (2007). Gamma Radiation Effects on the Electrical Parameters of Some Operational Amplifiers. The Second All African IRPA Regional Radiation Protection Congress. Ismailia.

19. Soliman, F. A. S., El-Ghanam, S. M. R., Abd El-Maksood, A. M. (2016). Impact of Outer Space Environment on Electronic Devices and Systems. Lambert Academic Publishing, Omni Scriptum GmbH and Co. KG., 142421.

Abd El-Maksood Ashraf Mosleh, PhD, Lecturer, Department of Electronics Engineering, Nuclear Materials Authority, Maadi, Cairo, Egypt, ORCID: http://orcid.org/0000-0001-8502-8042 